\title{
MODELAGEM NUMÉRICA EM ALTA RESOLUÇÃO PARA PREVISÃO DE GERAÇÃO DE ENERGIA EÓLICA NO CEARÁ
}

\author{
PAULO HENRIQUE SANTIAGO DE MARIA ${ }^{1}$, ALEXANDRE ARAÚJO COSTA² e $^{2}$ \\ SÉRGIO SOUSA SOMBRA ${ }^{2}$ \\ ${ }^{1}$ Fundação Cearense de Meteorologia e Recursos Hídricos - FUNCEME, \\ Departamento de Meteorologia e Oceanografia - DEMET. \\ ${ }^{2}$ Universidade Estadual do Ceará - UECE, Mestrado em Ciências Físicas Aplicadas - MCFA. \\ phenrique@funceme.br
}

Recebido Março 2008 - Aceito Setembro 2008

\begin{abstract}
RESUMO
Neste trabalho, foi utilizado um modelo de atmosfera de mesoescala para previsão de ventos em curto prazo para aplicações em geração de energia eólica. Diferentes resoluções espaciais e parametrizações foram testadas, sendo a comparação entre as simulações feita com base em uma metodologia estatística, que se utiliza de um conjunto de índices e medidas de erro amplamente utilizados em estudos meteorológicos e avaliações de modelos atmosféricos. Tal metodologia foi aplicada para escolha das melhores opções de espaçamento de grade horizontal, parametrização de turbulência e peso do relaxamento newtoniano na representação dos campos de vento do litoral cearense em quatro dias do período de transição entre as estações seca e chuvosa. Os testes revelam que, dentre as opções testadas, a configuração que melhor reproduz as observações ao longo do litoral, conta com espaçamento de grade horizontal de $1 \mathrm{~km}$, turbulência parametrizada com a versão anisotrópica do esquema proposto por Smagorinsky e escala de tempo do relaxamento newtoniano de $12 \mathrm{~h}$.

Palavras chave: previsão de ventos; modelagem atmosférica; energia eólica; intercomparação estatística.
\end{abstract}

\begin{abstract}
HIGH RESOLUTION ATMOSPHERIC MODELING TO FORECAST WIND ENERGY GENERATION IN CEARÁ

In the present work, a mesoscale atmospheric model was used for short-term wind forecast for applications on wind energy generation. Different spatial resolutions and parameterizations were tested, and the comparison among the simulations was based on a methodology, which uses a set of statistical indices and error indicators widely accepted in the Meteorology community when evaluating atmospheric models. Such methodology was utilized in order to choose the best options for horizontal grid spacing, turbulence parameterizations and nudging timescale when representing the wind field over the coast of Ceará State, in Northeast Brazil, in four days during the transition period between the dry and wet seasons. The tests reveal that, among the different options, the model setup, which reproduces better the observations along the coast is the one with a $1 \mathrm{~km}$ grid spacing, using an anisotropic Smagorinsky-type turbulence scheme and Newtonian relation timescale of $12 \mathrm{~h}$.
\end{abstract}

Keywords: wind forecast; atmospheric modeling; wind energy; statistical intercomparison.

\section{INTRODUÇÃO}

É reconhecido o elevado potencial eólico da região Nordeste do Brasil (NEB), em especial nas faixas litorâneas dos estados do Rio Grande do Norte e do Ceará, conforme já exposto por Sá (2001). Para utilização otimizada destes recursos, são necessários estudos, como o já referenciado, e desenvolvimento de técnicas adequadas que estejam ao alcance das instituições que possam empregá-los, culminando em benefícios à sociedade.

Um exemplo disso é o Atlas do Potencial Eólico do Estado do Ceará (2001). A previsão de ventos é outra prática, que ao contornar a incapacidade do homem em controlar o vento (Sánchez, 2006; Giebel, 2003), principal desvantagem da energia eólica, contribui para minorar o problema. Neste contexto, a modelagem atmosférica de mesoescala se insere 
como uma solução conveniente, por demandar investimento relativamente baixo e ter se revelado nas últimas décadas uma ferramenta confiável. Para que possa ser devidamente empregada, faz-se necessária a execução de testes de sensibilidade às opções oferecidas pelo modelo que permitam, mesmo de forma empírica, uma escolha criteriosa das opções mais adequadas. Neste ponto, a estatística tem um papel fundamental, possibilitando que se determine quantitativamente a melhor dentre as opções testadas.

Com base neste pensamento, o presente trabalho descreve uma metodologia que permite a escolha da melhor dentre duas ou mais opções do modelo que se queira comparar, por meio da estimativa de índices estatísticos e medidas de erro, calculados a partir de dados observados. Esta metodologia é ainda aplicada nas comparações de diferentes opções de espaçamento de
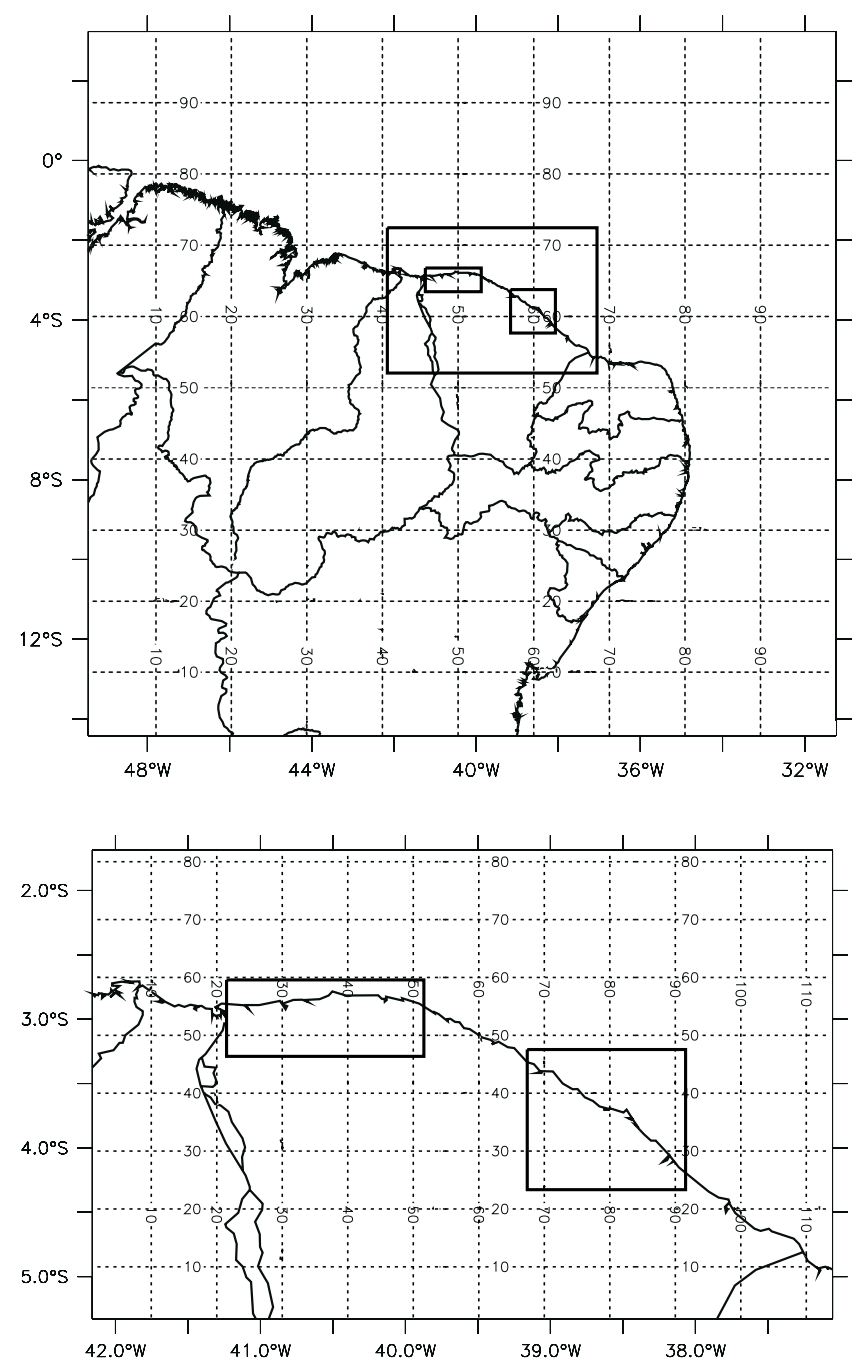

Figura 1 - Representação das grades horizontais usadas no modelo. grade horizontal, parametrizações de turbulência e relaxamento newtoniano, para as quais são apresentados os resultados e discussões.

\section{MATERIAL E MÉTODOS}

As simulações são efetuadas com o modelo RAMS (Cotton et al., 2003; Pielke et al., 1992) na sexta versão, ora usado operacionalmente em resolução mais baixa na Fundação Cearense de Meteorologia e Recursos Hídricos (Funceme), para os quatro primeiros dias do ano de 2005 sobre duas regiões litorâneas cearenses. O período simulado tem início em 01-JAN20050000 UTC e prolonga-se por 102 horas, correspondendo a uma fração do período de transição do regime local de ventos. O modelo é configurado com até quatro grades em dois níveis
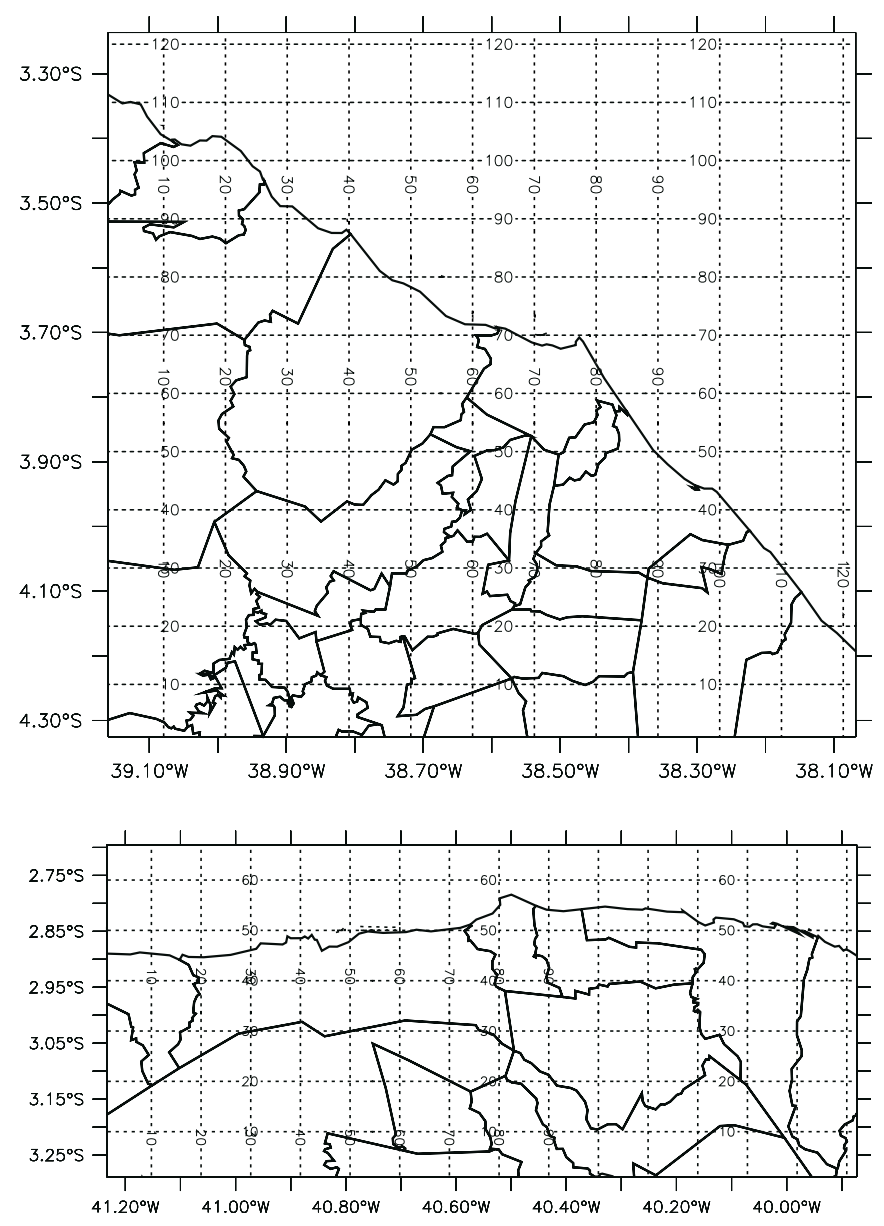
de aninhamento sucessivos, cobrindo respectivamente todo o NEB (exceto extremo sul do estado da Bahia) e uma porção do oceano Atlântico (Grade 1), a metade Norte do Ceará incluindo toda sua faixa litorânea (Grade 2), o litoral no entorno da capital Fortaleza, com aproximadamente $170 \mathrm{~km}$ de extensão (Grade 3 ) e, finalmente, a faixa litorânea na região norte do estado (Grade 4) com aproximadamente $150 \mathrm{~km}$ de extensão. A Tabela 1 fornece as especificações das grades, representadas na Figura 1.

Para todas as simulações é usada uma grade vertical de 32 pontos com espaçamento inicial de $60 \mathrm{~m}$, espaçamento máximo de $1 \mathrm{~km}$ e razão de expansão de 1,2893, de modo que o topo da atmosfera modelada encontra-se em aproximadamente 22668 m. A radiação é resolvida, para ondas curtas e longas, segundo o esquema de Harrington (1995), com atualização a cada 20 min simulados e variação longitudinal ativada. A microfísica de nuvens é parametrizada com 5 categorias de gelo (Walko et al., 1995), enquanto a convecção é resolvida com o esquema de Kuo (1974) a cada 20 min simulados, somente na grade externa. A interação com a superfície é representada via o sub-modelo LEAF2 (Walko et al., 2000), com 11 camadas de solo. Dados de análise do modelo global de resolução T126L28, disponíveis a cada $6 \mathrm{~h}$, mantido pelo Centro de Previsão de Tempo e Estudos Climáticos, CPTEC (http://www.cptec.inpe. br/), são empregados para determinação das condições iniciais e de fronteira com escala de tempo de relaxamento newtoniano de 20 min na fronteira e $12 \mathrm{~h}$ no topo. Para a caracterização do solo e superfície, são usados dados de índice de vegetação por diferença normalizada (NDVI), topografia, temperatura da superfície do mar (TSM) e tipo de superfície, fornecidos pelo serviço de apoio ao modelo, no endereço http://atmet.com.

Três opções de grade horizontal são testadas. Na primeira, de resolução mais baixa, apenas a primeira grade listada na Tabela 1 é usada. Na segunda, são ativadas as Grades 1 e 2 (espaçamento de $5 \mathrm{~km}$ ). Na terceira, todas as 4 grades são ativadas (espaçamento de $1 \mathrm{~km}$ ). Para comparação das parametrizações de turbulência são consideradas 2 das 6 opções disponíveis no modelo, correspondentes aos esquemas propostos por Mellor e Yamada (1982; 1974), e Smagorinsky (1963) na versão anisotrópica. Nos testes do peso do nudging central, são experimentadas três opções: sem relaxamento, escala de tempo central de $24 \mathrm{~h}$, e escala de tempo de $12 \mathrm{~h}$.

Cada um dos parâmetros do modelo supracitados é testado separadamente, numa seqüência pré-determinada. Primeiramente são comparadas as opções de espaçamento da grade horizontal. A opção de melhor desempenho é usada na comparação das parametrizações de turbulência. Os testes das opções de relaxamento newtoniano são feitos com uso das melhores opções para os parâmetros testados anteriormente. Tal procedimento garante apenas que o modelo não está configurado com o pior conjunto de opções, e não que este conjunto é o melhor possível.

As opções são intercomparadas através de um método que envolve uma série de índices estatísticos, aos quais são atribuídos escores, que por sua vez, têm pesos diferentes de acordo com sua relevância enquanto medida de erro ou semelhança entre as séries. Os índices usados na avaliação foram escolhidos visando a análise de diferentes aspectos das séries temporais como fase e amplitude, sendo eles o Viés estatístico (b), o Erro Absoluto Médio (A), o Erro Quadrático Médio (E), a Razão entre os Desvios padrão modelado e observado $(\mathrm{R} \sigma)$, o Erro Absoluto Médio dos desvios (A), o Erro Quadrático Médio dos desvios (E), o Índice de Concordância (Ic) e o Índice de Correlação (r), conforme apresentados e explicados na literatura (Buc-kley et al., 2004; Willmott, 1982; Steyn e Mckendry, 1988; Weber et al., 1982; Jolliffe e Ste-phenson, 2003; Pielke, 2001).

Nas formulações dos índices e das medidas de erro, emprega-se a definição de desvio das séries modeladas $\left(\phi^{\prime}{ }_{1}\right)$ e observadas $\left(\psi^{\prime}\right)$, onde:

$$
\begin{aligned}
& \phi_{1}^{\prime}=\phi_{\mathrm{l}}-\bar{\phi}_{\mathrm{l}} \\
& \psi_{\mathrm{l}}^{\prime}=\psi_{\mathrm{l}}-\bar{\psi}_{\mathrm{l}},
\end{aligned}
$$

sendo $\bar{\phi}_{1}$ e $\bar{\psi}_{1}$, respectivamente, as médias das séries modelada e observada, dadas por

Tabela 1 - Especificações das grades horizontais usadas nas simulações, onde Nx, Sx, Cx e Lx são, respectivamente, o número de pontos, a distância entre os pontos, a coordenada do centro da grade e a extensão do domínio na direção longitudinal, Ny, Dy, Cy e Ly são as mesmas grande-zas para a direção meridional e Dt corresponde ao passo de tempo para aquela grade.

\begin{tabular}{crrrrrrrrr}
\hline Grade & $N_{x}$ & \multicolumn{1}{c}{$N_{y}$} & \multicolumn{1}{c}{$D_{t}$} & \multicolumn{1}{c}{$D_{x}$} & \multicolumn{1}{c}{$D_{y}$} & \multicolumn{1}{c}{$C_{x}$} & \multicolumn{1}{c}{$C_{y}$} & \multicolumn{1}{c}{$L_{x}$} & \multicolumn{1}{c}{$L_{y}$} \\
\hline 1 & 100 & 100 & $30 \mathrm{~s}$ & $20 \mathrm{kml}$ & $20 \mathrm{~km}$ & $-5,67$ & $-40,33$ & $2000 \mathrm{kml}$ & $2000 \mathrm{~km}$ \\
2 & 114 & 82 & $10 \mathrm{~s}$ & $5 \mathrm{~km}$ & $5 \mathrm{~km}$ & $-3,55$ & $-39,64$ & $570 \mathrm{~km}$ & $410 \mathrm{~km}$ \\
3 & 122 & 122 & $2 \mathrm{~s}$ & $1 \mathrm{~km}$ & $1 \mathrm{~km}$ & $-3,87$ & $-38,59$ & $122 \mathrm{~km}$ & $122 \mathrm{~km}$ \\
4 & 152 & 67 & $2 \mathrm{~s}$ & $1 \mathrm{~km}$ & $1 \mathrm{~km}$ & $-2,98$ & $-40,56$ & $152 \mathrm{~km}$ & $67 \mathrm{~km}$ \\
\hline
\end{tabular}




$$
\begin{aligned}
& \overline{\phi_{i}}=\frac{1}{N} \sum_{i=1}^{n} \phi_{i} \\
& \overline{\psi_{i}}=\frac{1}{N} \sum_{i=1}^{n} \psi_{i}
\end{aligned}
$$

para as quais $\mathrm{N}$ é a quantidade de valores de cada série. Para cada índice em que uma opção se sai melhor, são atribuídos os escores referentes a este índice, de forma acumulativa, conforme os valores da Tabela 2.

O emprego deste método de avaliação estatística demanda a coleta prévia de dados observacionais. Este trabalho utiliza os resultados produzidos por duas campanhas distintas de coletas de séries temporais de vento. A primeira fonte de dados são as Plataformas de Coleta de Dados (PCDs) da Funceme, distribuídas em todo o território cearense, nas quais são registradas, dentre outras variáveis, médias de velocidade e direção do vento a cada hora em nível de $10 \mathrm{~m}$ acima da superfície, conforme documentado por Accioly Filho et al. (2004). As PCDs usadas nas comparações são listadas na Tabela 3. A segunda fonte de dados trata-se de uma iniciativa do Governo do Estado do Ceará em duas localidades litorâneas para aferição de seus potenciais eólicos: Torres Anemométricas (TAs) de Paracuru (lat.: 03²4'42,4”S, lon.: 3859’02,8’W) e Camocim (lat.: 02 51'56,7'S, lon.: 4053'09,2”W). Nesta campanha as componentes do vento foram medidas a cada $2 \mathrm{~s}$ com registros de médias e desvios padrão a cada $10 \mathrm{~min}$, em
3 níveis verticais $-60 \mathrm{~m}, 40 \mathrm{~m}$ e $20 \mathrm{~m}$ acima do nível do solo - para a velocidade e 2 níveis - $60 \mathrm{~m}$ e $40 \mathrm{~m}$ - para a direção (Consórcio Braselco-Melqart-CKC 2004a,b).

\section{RESULTADOS E DISCUSSÃO}

Os resultados das comparações com TAs são apresentados na forma de séries temporais de velocidade e direção do vento, além de tabelas com os valores dos índices estatísticos. Para as PCDs são apresentadas apenas tabelas com os escores obtidos por cada opção do modelo. A direção do vento registrada pela PCD de Aquiraz, apresenta valores incoerentes em relação ao que se poderia esperar para os padrões locais, tendo sido portanto, desconsiderada nas comparações. Na Tabela 4 são mostrados os resultados da comparação das opções de espaçamento da grade horizontal com PCDs.

Pela Tabela 4, em apenas uma localidade o modelo apresenta melhores estimativas de velocidade do vento, quando a grade é espaçada em $20 \mathrm{~km}$. Para outras duas localidades, a melhor opção é o espaçamento de $5 \mathrm{~km}$. Entretanto, para a maioria das PCDs, o melhor resultado foi obtido com grade espaçada em $1 \mathrm{~km}$. Nas estimativas de direção do vento é maior o equilíbrio entre os resultados obtidos com os diferentes espaçamentos de grade, mas o espaçamento em $1 \mathrm{~km}$ pode ser considerado superior, visto que obteve mais escores para um maior número de PCDs.

A Figura 2 apresenta as séries temporais de velocidade e direção do vento, referentes aos sensores instalados a 60 $\mathrm{m}$ da superfície na localidade de Paracuru e os respectivos

Tabela 2 - Formulação dos índices e medidas de erro estatístico e suas respectivas quantidades de escores.

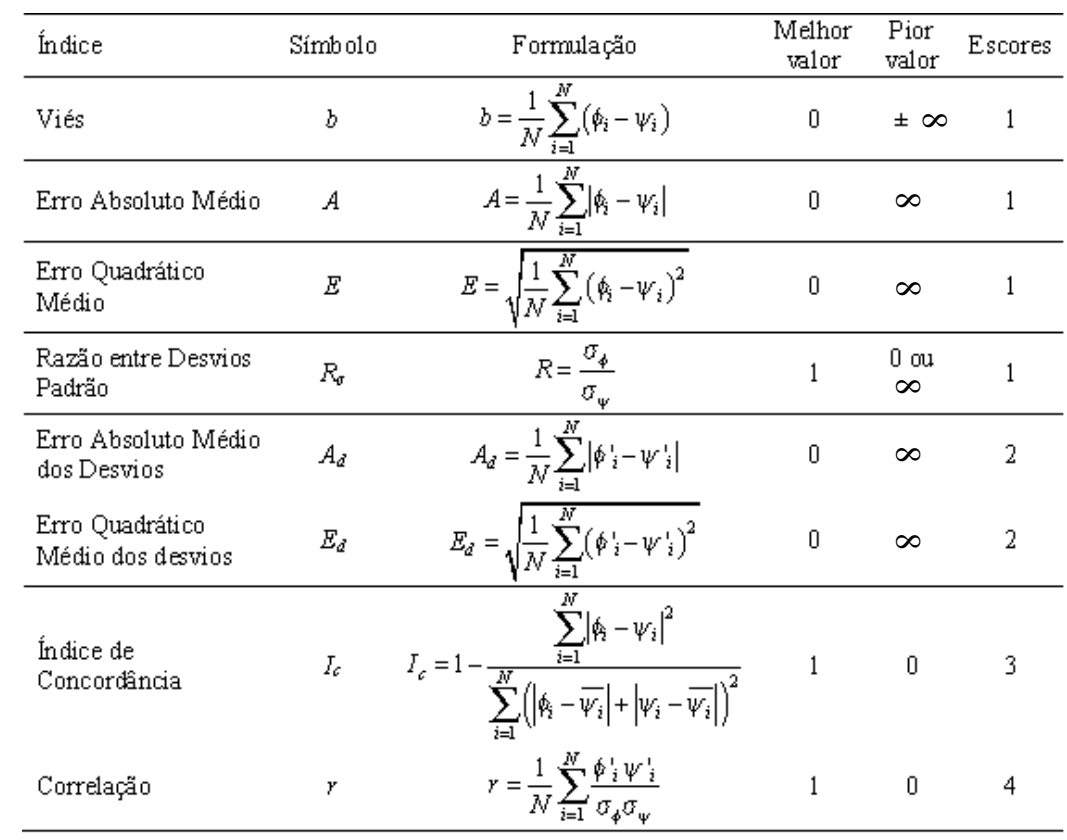


Tabela 3 - PCDs usadas nas comparações com os resultados do modelo e suas respectivas latitude, longitude, altitude modelada e grade do modelo onde está contida.

\begin{tabular}{lccrc}
\hline Localidade & Latitude & Longitude & \multicolumn{1}{c}{ Altitude } & Grade \\
\hline Beberibe & $04^{\circ} 14^{\prime} 29,9^{\prime \prime} \mathrm{S}$ & $38^{\circ} 12^{\prime} 05,3^{\prime \prime} \mathrm{W}$ & $31,46 \mathrm{ml}$ & 3 \\
Aquiraz & $04^{\circ} 00^{\prime} 22,7^{\prime \prime} \mathrm{S}$ & $38^{\circ} 23^{\prime} 21,7^{\prime \prime} \mathrm{W}$ & $46,30 \mathrm{~m}$ & 3 \\
Maranguape & $03^{\circ} 59^{\prime} 06,1^{\prime \prime} \mathrm{S}$ & $38^{\circ} 47^{\prime} 17,5^{\prime \prime} \mathrm{W}$ & $163,00 \mathrm{~m}$ & 3 \\
Fortaleza & $03^{\circ} 43^{\prime} 44,0^{\prime \prime} \mathrm{S}$ & $38^{\circ} 33^{\prime} 50,0^{\prime \prime} \mathrm{W}$ & $4,26 \mathrm{~m}$ & 3 \\
Caucaia & $03^{\circ} 44^{\prime} 16,1^{\prime \prime} \mathrm{S}$ & $38^{\circ} 41^{\circ} 04,2^{\prime \prime} \mathrm{W}$ & $38,79 \mathrm{ml}$ & 3 \\
São Gonçalo do Amarante & $03^{\circ} 39^{\prime} 00,8^{\prime \prime} \mathrm{S}$ & $38^{\circ} 56^{\prime} 32,6^{\prime \prime} \mathrm{W}$ & $63,08 \mathrm{~m}$ & 3 \\
Pacajus & $04^{\circ} 11^{\prime} 24,0^{\prime \prime} \mathrm{S}$ & $38^{\circ} 29^{\prime} 54,2^{\prime \prime} \mathrm{W}$ & $92,22 \mathrm{ml}$ & 3 \\
Acaraú & $02^{\circ} 52^{\prime} 35,4^{\prime \prime} \mathrm{S}$ & $39^{\circ} 59^{\prime} 33,4^{\prime \prime} \mathrm{W}$ & $7,78 \mathrm{ml}$ & 4 \\
Granja & $03^{\circ} 09^{\prime} 53,2^{\prime \prime} \mathrm{S}$ & $40^{\circ} 51^{\prime} 40,6^{\prime \prime} \mathrm{W}$ & $39,73 \mathrm{~m}$ & 4 \\
Barroquinhta & $02^{\circ} 55^{\prime} 48,2^{\prime \prime} \mathrm{S}$ & $41^{\circ} 07^{\circ} 07,3^{\prime \prime} \mathrm{W}$ & $5,39 \mathrm{ml}$ & 4 \\
\hline
\end{tabular}

Tabela 4 - Total de escores obtidos com as opções de espaçamento de grade horizontal, para velocidade e direção do vento em cada PCD.

\begin{tabular}{lccc|cccc}
\hline & \multicolumn{3}{c}{ Velocidade } & \multicolumn{3}{c}{ Direção } \\
Localidade & $20 \mathrm{Km}$ & $5 \mathrm{Km}$ & $1 \mathrm{Km}$ & $20 \mathrm{Km}$ & $5 \mathrm{Km}$ & $1 \mathrm{Km}$ \\
\hline Beberibe & 11 & 4 & 0 & 1 & 0 & 14 \\
Aquiraz & 2 & 1 & 12 & - & - & - \\
Maranguape & 0 & 14 & 1 & 2 & 12 & 1 \\
Fortaleza & 1 & 0 & 14 & 5 & 0 & 10 \\
Caucaia & 1 & 0 & 14 & 0 & 9 & 6 \\
São Gonçalo do Amarante & 0 & 5 & 10 & 1 & 0 & 14 \\
Pacajus & 1 & 5 & 9 & 0 & 14 & 1 \\
Acaraú & 1 & 1 & 13 & 8 & 3 & 4 \\
Grarija & 0 & 15 & 0 & 8 & 5 & 2 \\
Barroquinha & 1 & 2 & 12 & 0 & 1 & 14 \\
\hline Total de localidades & 1 & 2 & 7 & 2 & 3 & 4 \\
\hline
\end{tabular}

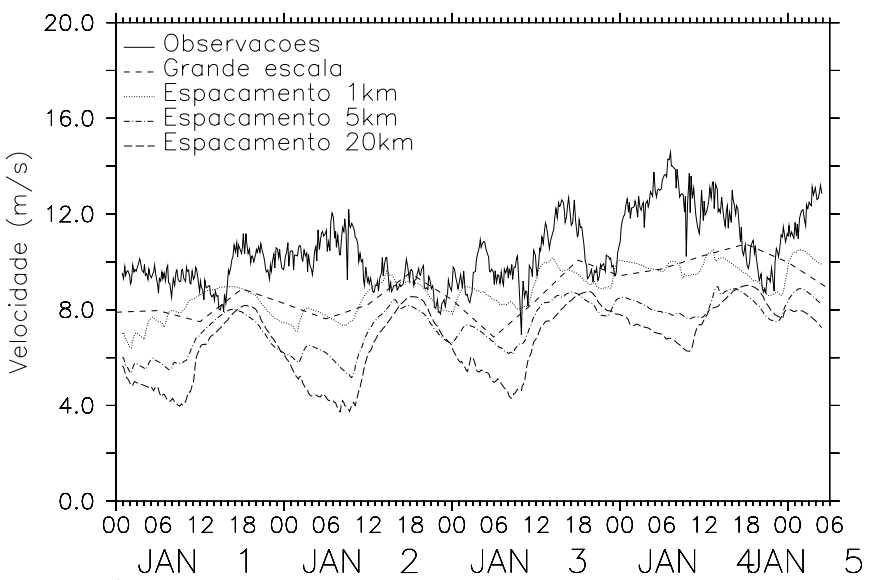

a)

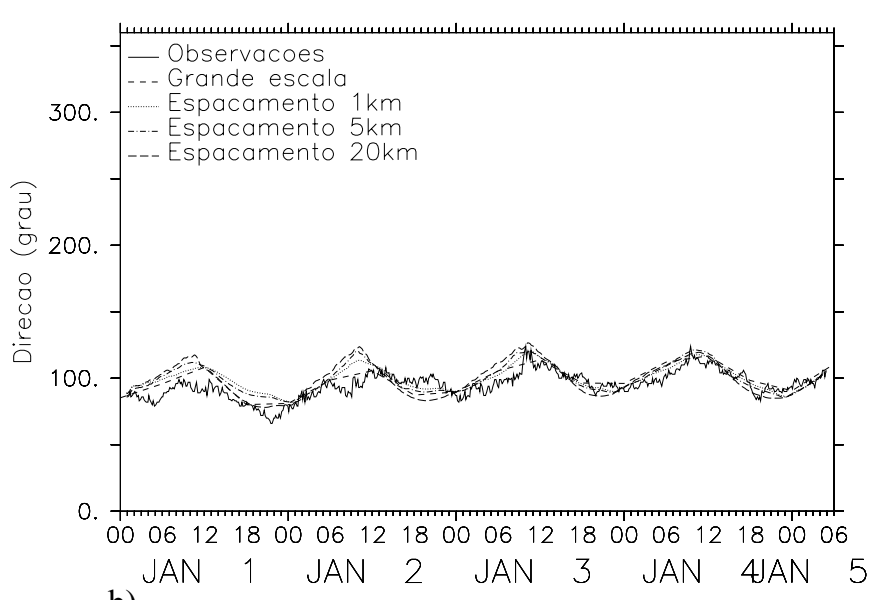

b)

Figura 2 - Séries temporais de (a) velocidade e (b) direção do vento resultantes de observações, dados de grande escala e simulações com diferentes opções de espaçamento horizontal, em Paracuru. 
resultados do modelo obtidos com espaçamentos de grade em $20 \mathrm{~km}, 5 \mathrm{~km}$ e $1 \mathrm{~km}$. Para a velocidade observada, destaca-se a ausência de ciclo diário, com valores variando entre 7,0 m/s e $15 \mathrm{~m} / \mathrm{s}$, que o modelo tratou de subestimar com qualquer das opções de grade testadas. Vale notar também, que o modelo apresenta ciclo diário mais pronunciado conforme menor a resolução da grade, o que sugere melhores índices estatísticos para as simulações com menor espaçamento. Para a direção do vento em Paracuru (Figura 2b), tanto as simulações quanto os registros da torre anemométrica revelam um pronunciado ciclo diário, com extremos ocorrendo entre 18 UTC e 00 UTC, e entre 06 UTC e 12 UTC. Neste caso o modelo acerta em boa parte do período, além de concordar com máximos e mínimos observados. Entretanto, não fica evidente qual opção de grade é responsável por melhores resultados, o que é feito na Tabela 5 com os índices estatísticos.

$\mathrm{Na}$ Figura 3 são mostradas as séries temporais de velocidade e direção dos sensores ins-talados a $60 \mathrm{~m}$ da superfície na localidade de Camocim, e os respectivos resultados do modelo com diferentes opções de espaçamento da grade horizontal. Desta vez, as observações revelam um pronunciado ciclo diário de velocidade, com máximos que alcançam 17 $\mathrm{m} / \mathrm{s}$ e mínimos acima de $3 \mathrm{~m} / \mathrm{s}$, configurando um padrão que o modelo foi capaz de representar, ainda que subestimando os ventos mais intensos.

Com qualquer das opções de grade horizontal, o modelo apresenta boa concordância na representação da direção do vento da localidade de Camocim (Figura 3a), caracterizada pelo evidente ciclo diário. Ao que se pode perceber, os resultados obtidos com a grade espaçada em $20 \mathrm{~km}$ é responsável por maiores desvios em relação às outras opções.

A Tabela 5 apresenta os índices estatísticos e medidas de erro para cada opção de espaçamento horizontal, relativos

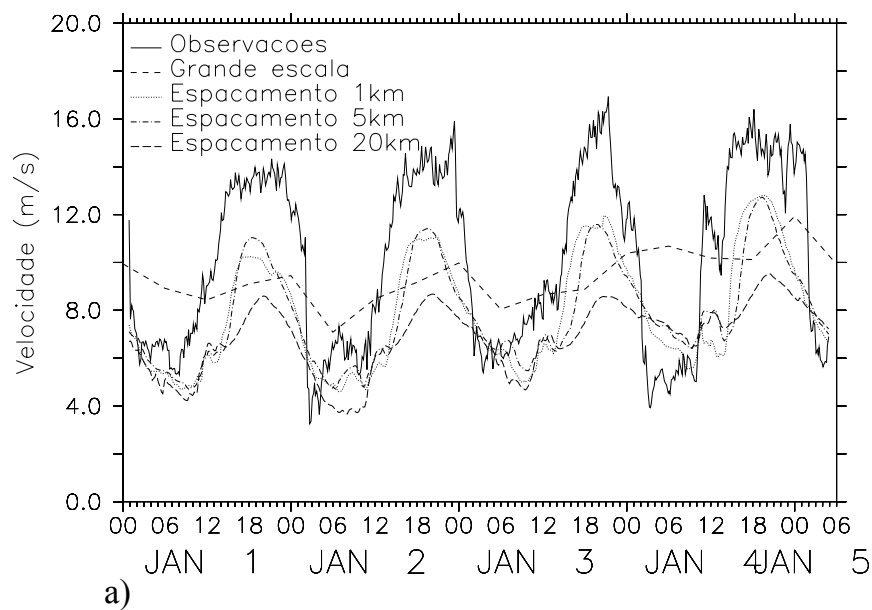

à direção e velocidade do vento a $60 \mathrm{~m}$ da superfície para as localidades de Paracuru e Camocim. Nela, nota-se que diminuem os erros nas estimativas de velocidade e aumentam os valores dos índices estatísticos, conforme o espaçamento da grade diminui, seja na localidade de Paracuru ou Camocim, culminando numa maior quantidade de escores para o experimento com espaçamento de grade em $1 \mathrm{~km}$.

Na Tabela 6 são apresentados os escores obtidos com cada opção de parametrização de turbulência, quando feitas as comparações com os registros das PCDs, para as quais o esquema de Smagorinsky atinge mais escores em 8 das 9. Entretanto, conforme a quantidade de escores, cada esquema se mostrou melhor em metade das localidades na representação da intensidade do vento, assinalando um empate.

As Figuras 4 e 5 mostram as séries de velocidade e direção do vento observadas e mo-deladas com as diferentes parametrização de turbulência, para uma altitude de $60 \mathrm{~m}$ acima da superfície, respectivamente para as TAs de Paracuru e Camocim.

$\mathrm{Na}$ Figura 4 a vê-se o nítido ciclo diário de velocidade do vento estimado pelo modelo com parametrização de turbulência de Mellor \& Yamada para a TA de Paracuru, não condizente com as observações, além da subestimação desses valores em qualquer instante da série temporal. Ao mesmo tempo, a parametrização de Smagorinsky apresenta resultados mais plausíveis, concordando com as observações ao detectar a ausência de ciclo diário e, ainda que também apresente subestimações na maior parte do período, obtém acertos significativos.

A direção do vento em Paracuru (Figura 4b) tem seu ciclo diário bem representado pelo modelo com turbulência resolvida com o esquema de Smagorinsky, com erros mais evidentes no primeiro dia de simulação. Entre 06 UTC e 12 UTC, a parametrização de Mellor \& Yamada leva a desvios mais acentuados, que tendem a se atenuar com o passar dos

Figura 3 - Séries temporais de (a) velocidade e (b) direção do vento resultantes de observações, dados de grande escala e simulações com diferentes opções de espaçamento horizontal, em Ca-mocim. 
Tabela 5 - Intercomparação das opções de espaçamento da grade horizontal. Velocidade e dire-ção do vento observado e modelado nas localidades de Paracuru e Camocim para o nível de $60 \mathrm{~m}$ acima da superfície. Estimativas estatísticas de viés (b), Erro absoluto médio (A), Erro quadrático médio (E), Razão entre desvios padrão $\left(\mathrm{R}_{\sigma}\right)$, Erro absoluto médio dos desvios (Ad), erro quadrático médio dos desvios (Ed), índices de concordância (Ic) e correlação (r), e a quanti-dade de escores acumulada por cada opção.

\begin{tabular}{|c|c|c|c|c|c|c|c|c|c|c|c|}
\hline & & Opção & $b$ & $A$ & $E$ & $R_{\sigma}$ & $A_{d}$ & $\overline{E_{d}}$ & $I_{c}$ & $r$ & Escores \\
\hline \multirow{6}{*}{ 㓂 } & \multirow{3}{*}{$\$$} & $20 \mathrm{Km}$ & $-3,72$ & $\overline{3,73}$ & 4,16 & 0,97 & 1,53 & 1,83 & 0,35 & 0,23 & 1 \\
\hline & & $5 \mathrm{Km}$ & $-3,07$ & 3,07 & 3,37 & 1,41 & 1,14 & 1,39 & 0,41 & 0,42 & 0 \\
\hline & & $1 \mathrm{Km}$ & $-1,62$ & 1,71 & 2,03 & 1,51 & 0,99 & 1,20 & 0,54 & 0,54 & 14 \\
\hline & \multirow{3}{*}{ 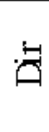 } & $20 \mathrm{Km}$ & 4,38 & 8,66 & 10,91 & 0,78 & 7,75 & 9,86 & 0,76 & 0,65 & 1 \\
\hline & & $5 \mathrm{Km}$ & 4,94 & 7,57 & 9,49 & 0,93 & 6,55 & 8,09 & 0,78 & 0,69 & 1 \\
\hline & & $1 \mathrm{Km}$ & 4,70 & 6,64 & 8,39 & 1,08 & 5,61 & 6,93 & 0,81 & 0,74 & 13 \\
\hline \multirow{6}{*}{ 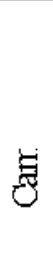 } & \multirow{3}{*}{$\vec{D}$} & $20 \mathrm{Km}$ & $-3,23$ & 3,68 & 4,30 & 1,46 & 2,41 & 2,83 & 0,61 & 0,71 & 0 \\
\hline & & $5 \mathrm{Km}$ & $-2,22$ & 2,72 & 3,22 & 2,13 & 1,90 & 2,33 & 0,74 & 0,81 & 0 \\
\hline & & $1 \mathrm{Km}$ & $-2,20$ & 2,55 & 2,98 & 2,38 & 1,64 & 2,01 & 0,79 & 0,86 & 15 \\
\hline & \multirow{3}{*}{ 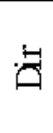 } & $20 \mathrm{Km}$ & $-8,16$ & 14,95 & 18,77 & 19,76 & 12,69 & 16,85 & 0,83 & 0,77 & 0 \\
\hline & & $5 \mathrm{Km}$ & $-7,56$ & 12,52 & 16,13 & 22,51 & 10,42 & 14,25 & 0,89 & 0,84 & 0 \\
\hline & & $1 \mathrm{KM}$ & $-6,87$ & 9,50 & 13,40 & 22,75 & 8,14 & 11,50 & 0,92 & 0,90 & 15 \\
\hline
\end{tabular}

Tabela 6 - Total de escores obtidos com turbulência parametrizada por Mellor \& Yamada (M\&Y) e a versão anisotrópica de Smagorinsky (sma), para velocidade e direção do vento de cada PCD.

\begin{tabular}{lcc|cc}
\hline & \multicolumn{2}{c}{ Velocidade } & \multicolumn{2}{c}{ Direção } \\
Localidade & M\&Y & SMA & M\&Y & SMA \\
\hline Beberibe & 5 & 10 & 1 & 14 \\
Aquiraz & 11 & 4 & - & - \\
Maranguape & 15 & 0 & 7 & 8 \\
Fortaleza & 1 & 14 & 0 & 15 \\
Caucaia & 5 & 10 & 0 & 15 \\
São Gronçalo do Annarante & 4 & 11 & 1 & 14 \\
Pacajus & 15 & 0 & 15 & 0 \\
Acaraú & 3 & 12 & 2 & 13 \\
Granja & 10 & 5 & 5 & 10 \\
Barroquinha & 15 & 0 & 5 & 10 \\
\hline Total de localidades & 5 & 5 & 1 & 8 \\
\hline
\end{tabular}

dias. Para boa parte dos demais trechos do período, os resultados apresentam acertos consideráveis.

Na Figura 5a, ambas as parametrizações de turbulência levam a resultados que subestimam os máximos de velocidade do vento da localidade de Camocim, ainda que representando bem a tendência de ciclo diário. Pode-se notar ainda, que a parametrização de Smagorinsky é responsável por menores desvios que a de Mellor \& Yamada, especialmente entre o segundo e o terceiro dia de simulação.

Ao mesmo tempo, a direção do vento em Camocim (Figura 5b) é representada com razoável concordância pelo modelo com qualquer das opções de turbulência testadas. As maiores discordâncias, ocorrem nos momentos em que o vento passa a se originar de SE. Ainda assim, os desvios relativos às observações produzidos com essas opções parecem equivalentes, exceto pelo comportamento produzido com o esquema de Mellor \& Yamada nas primeiras horas do terceiro dia do período.

$\mathrm{Na}$ Tabela 7 são fornecidos os índices estatísticos correspondentes às séries temporais mostradas nas Figuras $4 \mathrm{e}$ 5. Apesar dos valores significativos para o viés e demais medidas de erro, com qualquer das parametrizações de turbulência o modelo obteve elevados índices de correlação para a localidade 
de Camocim, seja para velocidade ou para a direção do vento. As correlações entre velocidades modelada e observada para a TA de Paracuru revelam a dificuldade do modelo em estimar um comportamento irregular do vento. A pendência encontrada na Tabela 6, na qual cada opção se mostra melhor em metade das PCDs, é sanada com o a comparação com as TAs, onde a parametrização de Smagorinsky maior quantidade de escores.

O total de escores obtidos na avaliação do modelo com diferentes opções de relaxamento newtoniano é dado na Tabela 8, para velocidade e direção do vento em cada PCD. $\mathrm{Na}$ representação da velocidade do vento, o modelo com relaxamento mais forte (12h) obtém mais escores na comparação com todas as PCDs. Esta opção também se mostra mais adequada na representação da direção, visto que obteve mais escores em 6 das 9 séries temporais disponíveis.

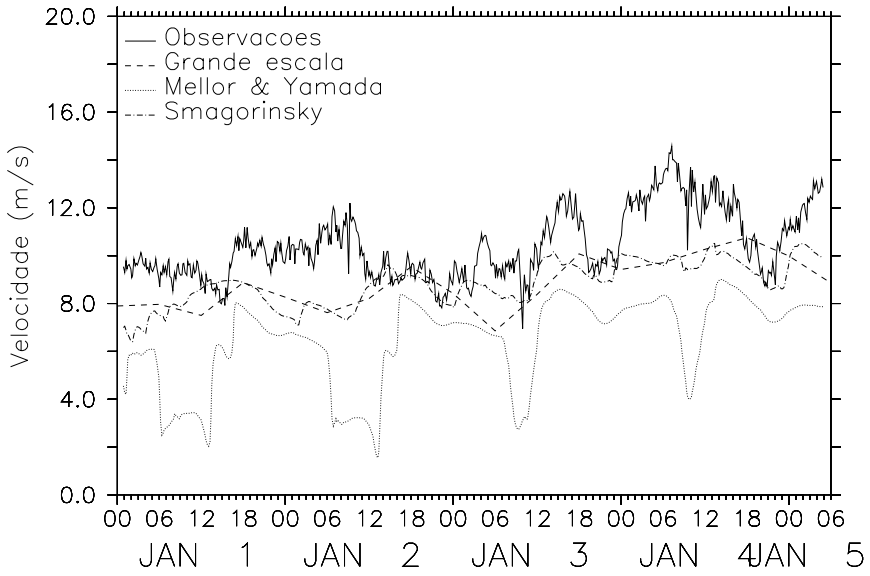

a)
A Figura 6a mostra que, ao estimar a velocidade do vento da localidade de Paracuru, o modelo gera resultados semelhantes entre si quando configurado com um peso não nulo. Por outro lado, o modelo com relaxamento nulo gera resultados que divergem significativamente das observações em boa parte do período, com alguns acertos pontuais e uma considerável concordância na segunda metade do terceiro dia que não devem ser suficientes para a obtenção de índices estatísticos melhores que as opções de relaxamento não-nulo.

Para a direção do vento em Paracuru (Figura 6b), valem as mesmas considerações sobre as opções com relaxamento mais fraco e mais forte feitas para a velocidade. A partir da segunda metade do segundo dia, os resultados obtidos com o modelo sem nudging passam a divergir significativamente, e a sensibilidade ao ciclo diário se perde.

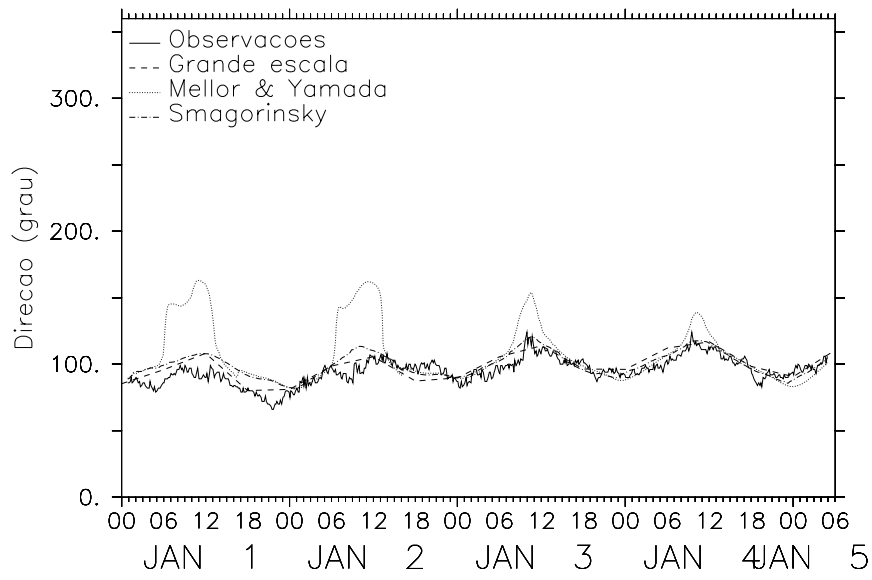

b)

Figura 4 - Séries temporais de (a) velocidade e (b) direção do vento resultantes de observações, dados de grande escala e simulações com diferentes parametrizações de turbulência, em Paracuru.

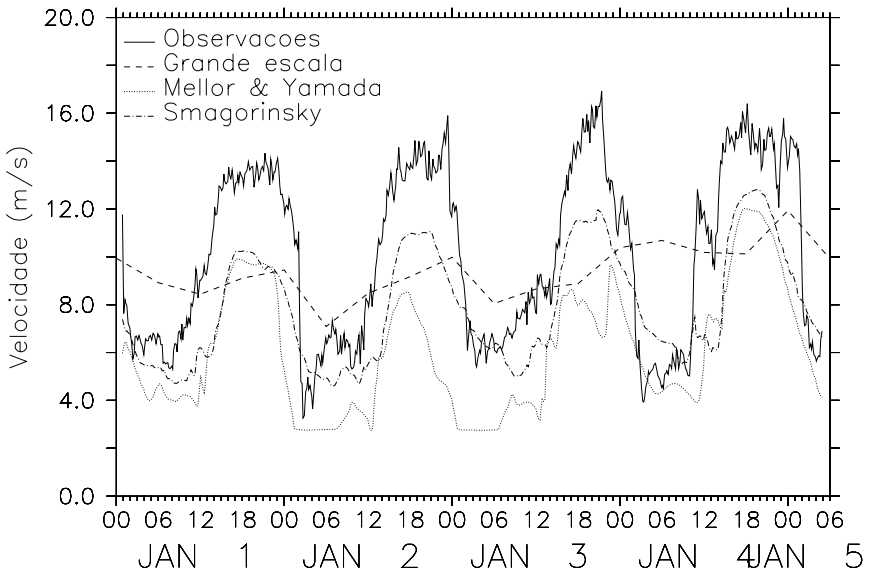

a)

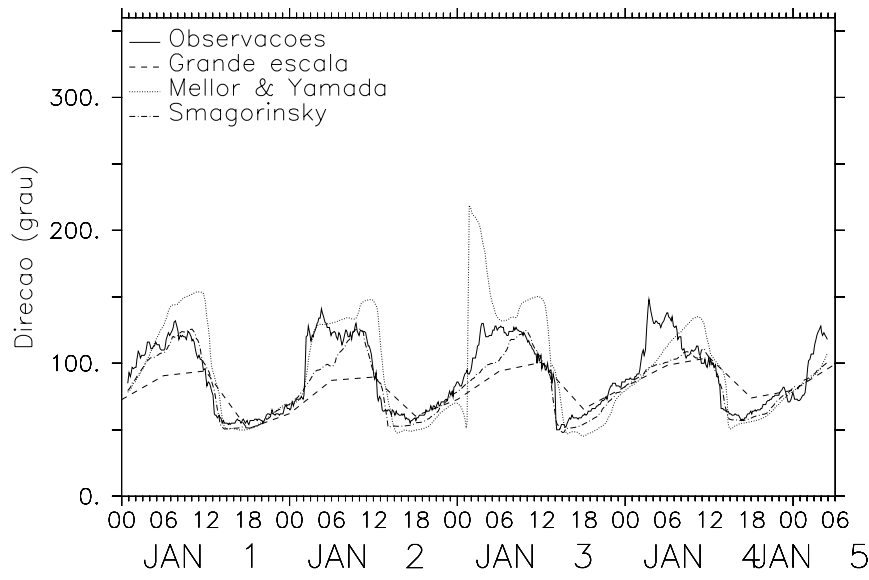

b)

Figura 5 - Séries temporais de (a) velocidade e (b) direção do vento resultantes de observações, dados de grande escala e simulações com diferentes parametrizações de turbulência, em Camocim. 
Tabela 7 - Intercomparação de parametrizações de turbulência. Índices estatísticos para velocidade e direção do vento nas localidades de Camocim e Paracuru, para o nível de $60 \mathrm{~m}$ acima da superfície.

\begin{tabular}{|c|c|c|c|c|c|c|c|c|c|c|c|}
\hline & & Modelo & $b$ & $A$ & $E$ & $R_{\sigma}$ & $A_{d}$ & $E_{d^{\prime}}$ & $I_{c}$ & $r$ & Esc. \\
\hline \multirow{4}{*}{ 唲 } & \multirow{2}{*}{$\Phi$} & M\&Y & $-3,97$ & 3,97 & 4,41 & 0,77 & 1,49 & 1,87 & 0,18 & 0,38 & 1 \\
\hline & & SMA & $-1,62$ & 1,71 & 2,03 & 1,52 & 0,99 & 1,20 & 0,42 & 0,54 & 14 \\
\hline & \multirow{2}{*}{ 㫣 } & $\mathrm{M} \& \mathrm{Y}$ & 12,15 & 14,72 & 23,40 & 0,44 & 14,92 & 19,99 & 0,10 & 0,44 & 0 \\
\hline & & SMA & 4,70 & 6,64 & 8,39 & 1,08 & 5,61 & 6,93 & 0,59 & 0,74 & 15 \\
\hline \multirow{2}{*}{$\Xi$} & \multirow{2}{*}{9} & $\overline{\mathrm{M} \& \mathrm{Y}}$ & $-4,08$ & 4,10 & 4,69 & 1,41 & 1,81 & 2,31 & 0,57 & 0,78 & 1 \\
\hline & & SMA & $-2,20$ & 2,55 & 2,98 & 1,54 & 1,64 & 2,01 & 0,73 & 0,86 & 14 \\
\hline \multirow{2}{*}{$\stackrel{\Xi}{U}$} & \multirow{2}{*}{ 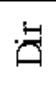 } & $\mathrm{M} \& \mathrm{Y}$ & 4,98 & 17,33 & 24,93 & 0,68 & 18,00 & 24,43 & 0,68 & 0,79 & 1 \\
\hline & & SMA & $-6,87$ & 9,50 & 13,40 & 1,17 & 8,14 & 11,50 & 0,88 & 0,90 & 14 \\
\hline
\end{tabular}

Tabela 8 - Total de escores obtidos pelas simulações sem relaxamento newtoniano, com relaxamento relativamente mais fraco (24h) e com relaxamento relativamente mais forte $(12 \mathrm{~h})$, para velocidade e direção de cada PCD.

\begin{tabular}{lccc|cccc}
\hline & \multicolumn{3}{c}{ Velocidade } & \multicolumn{3}{c}{ Direção } \\
Localidade & $\mathrm{s} /$ & mudging & $\mathrm{t}=24 \mathrm{~h}$ & $\mathrm{t}=12 \mathrm{~h}$ & $\mathrm{~s} /$ mudging & $\mathrm{t}=24 \mathrm{~h}$ & $\mathrm{t}=12 \mathrm{~h}$ \\
\hline Beberibe & 4 & 4 & 7 & 1 & 14 & 0 \\
Aquiraz & 1 & 2 & 12 & - & - & - \\
Maranguape & 1 & 6 & 8 & 1 & 3 & 11 \\
Fortaleza & 0 & 0 & 15 & 0 & 8 & 7 \\
Caucaia & 0 & 1 & 14 & 1 & 0 & 14 \\
Säo Gonçalo do Amarante & 1 & 1 & 13 & 1 & 1 & 13 \\
Pacajus & 1 & 2 & 12 & 3 & 0 & 12 \\
Acaraún & 1 & 3 & 11 & 1 & 8 & 6 \\
Granja & 1 & 0 & 14 & 0 & 0 & 15 \\
Barroquinha & 2 & 5 & 8 & 1 & 0 & 14 \\
\hline Total de localidades & 0 & 0 & 10 & 0 & 3 & 6 \\
\hline
\end{tabular}

Em relação à TA de Camocim (Figura 7), as séries temporais de velocidade produzidas com relaxamento não nulo apresentam forte semelhança entre si, sendo a opção de nudging mais fraco responsável por uma variabilidade sensivelmente maior. Ao mesmo tempo, a ausência de relaxamento leva o modelo a resultados com desvios aparentemente maiores, maior variabilidade que as outras opções, e acertos razoáveis em alguns trechos.

Exceto pelo desvio que ocorre por volta de 06 UTC em cada dia, a presença de relaxamento newtoniano leva o modelo a uma excelente representação da série temporal de direção para localidade de Camocim, como se pode verificar na Figura $7 \mathrm{~b}$. A maior diferença entre os resultados com nudging mais fraco e mais forte, se dá por conta da maior variabilidade gerada por aquela opção. A partir da metade do segundo dia, o modelo configurado sem relaxamento passa a apresentar variações intensas que não correspondem às observações, até apresentar, por volta da metade do terceiro dia, uma maior estabilidade não condizente com as observações.

A Tabela 9 expõe os índices estatísticos referentes às comparações das opções de relaxamento newtoniano para velocidade e direção do vento das TAs de Paracuru e Camocim. Nela, verifica-se como são pequenas as diferenças entre o modelo com nudging mais fraco (24h) e mais forte (12h), especialmente pelos índices de correlação e concordância. Também se destaca a diminuição do desempenho, quando adotado um peso nulo para 
o nudging central, o que se constata pelos valores mais baixos para correlação entre velocidades e maiores medidas de erro entre direção modelada e observada. Os resultados das Tabela 8 e Tabela 9 concordam ao apon-tar que o peso maior para o relaxamento newtoniano leva a melhores resultados.

Ao que se pode perceber, o dado de grande escala subestima a intensidade do vento em Paracuru (Figuras 2a, 4a e $6 a)$ e mostra-se pouco sensível às variações do ciclo diário de Camocim (Figuras 3a, 5a e 7a). A direção do vento em Paracuru (Figuras 2b, 4b e 6b) é apresentada com boa concordância com as observações, enquanto em Camocim (Figuras 3b, 5b e 7b), apa-recem divergências que dependem do horário. Além do aumento da variabilidade temporal, é de se considerar o valor que o modelo de mesoescala agrega ao dado de grande escala, especial-mente para a velocidade e direção do vento de Camocim.
Nas Figuras 8 e 9 são mostrados, respectivamente para as Grades 3 e 4, os mapas da in-tensidade do vento, em média ao longo de quatro dias, com vetores indicando a direção, curvas de nível da topografia (em branco) e divisão política (em preto) para os horários de (a) 06 UTC, (b) 12 UTC, (c) 18 UTC e (d) 24 UTC.

$\mathrm{Na}$ Grade 3 (Figura 8a-d), o vento é caracterizado pela uniformidade sobre o oceano e pela influência da topografia sobre o continente, resultando numa evidente variabilidade espacial. Verifica-se um acentuado gradiente da intensidade do vento ao longo da linha da costa associado à mudança do comprimento de rugosidade. O sistema de brisa pode ser identificado pela alteração na direção e pela variação da velocidade do vento.

Para a Grade 4 (Figura 9a-d), quando comparada à Grade 3 , o efeito da brisa sobre a circulação de grande escala parece

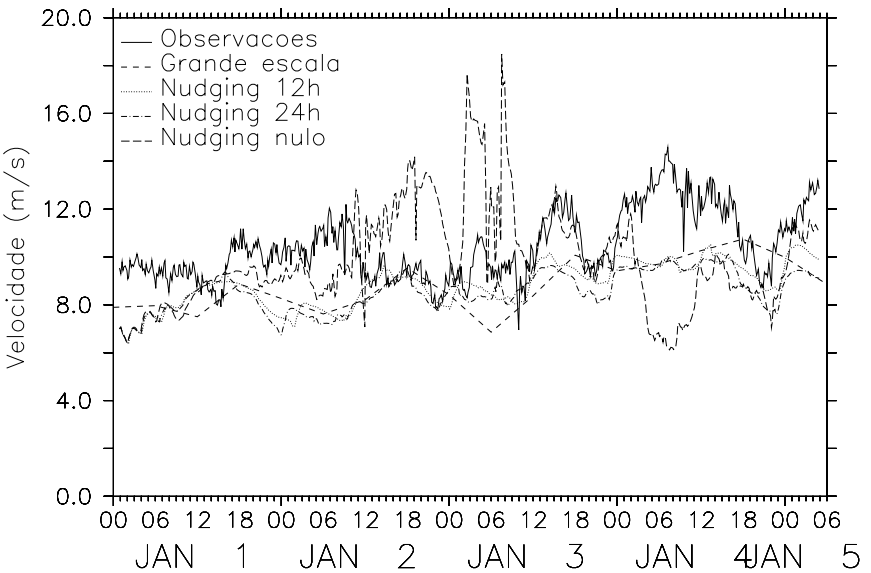

a)

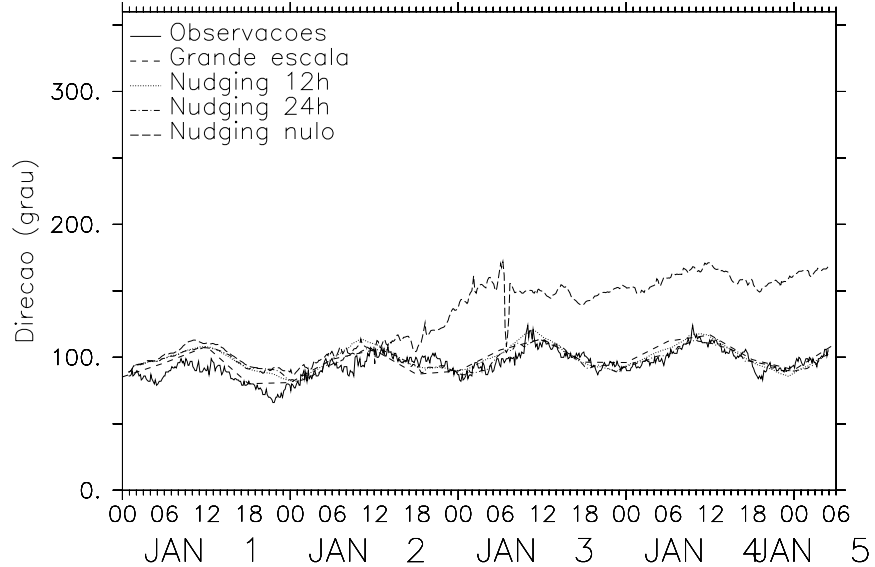

b)

Figura 6 - Séries temporais de (a) velocidade e (b) direção do vento resultantes de observações, dados de grande escala e simulações com diferentes opções de relaxamento newtoniano, em Paracuru.

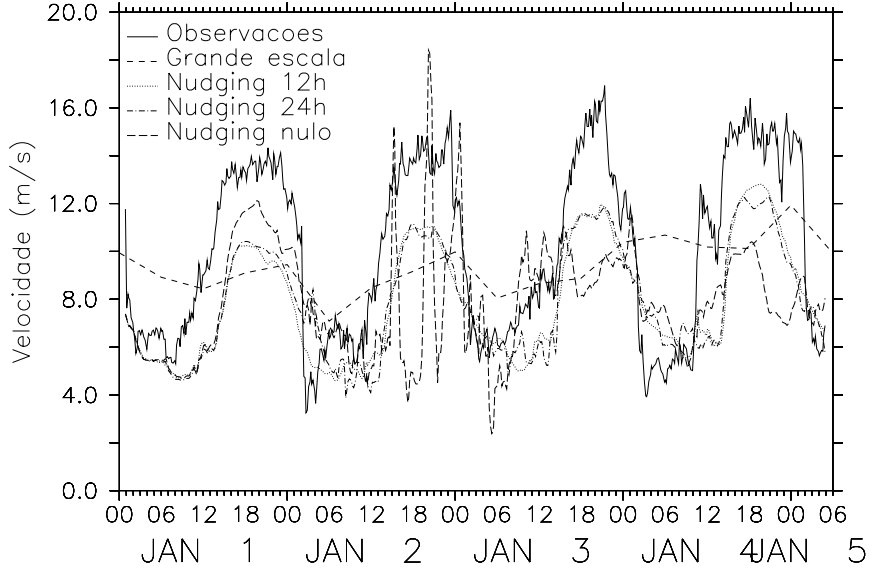

a)

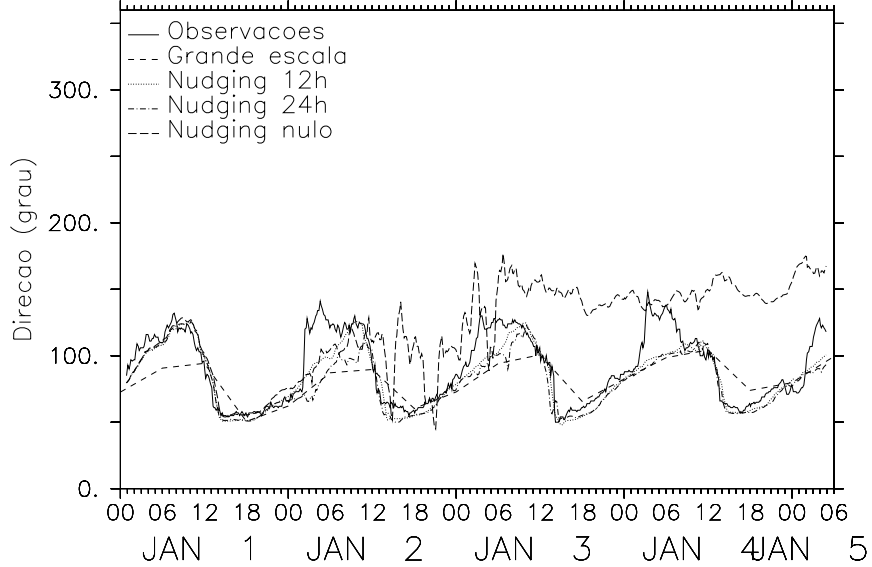

b)

Figura 7 - Séries temporais de (a) velocidade e (b) direção do vento resultantes de observações, dados de grande escala e simulações com diferentes opções de relaxamento newtoniano, em Camocim. 
a)
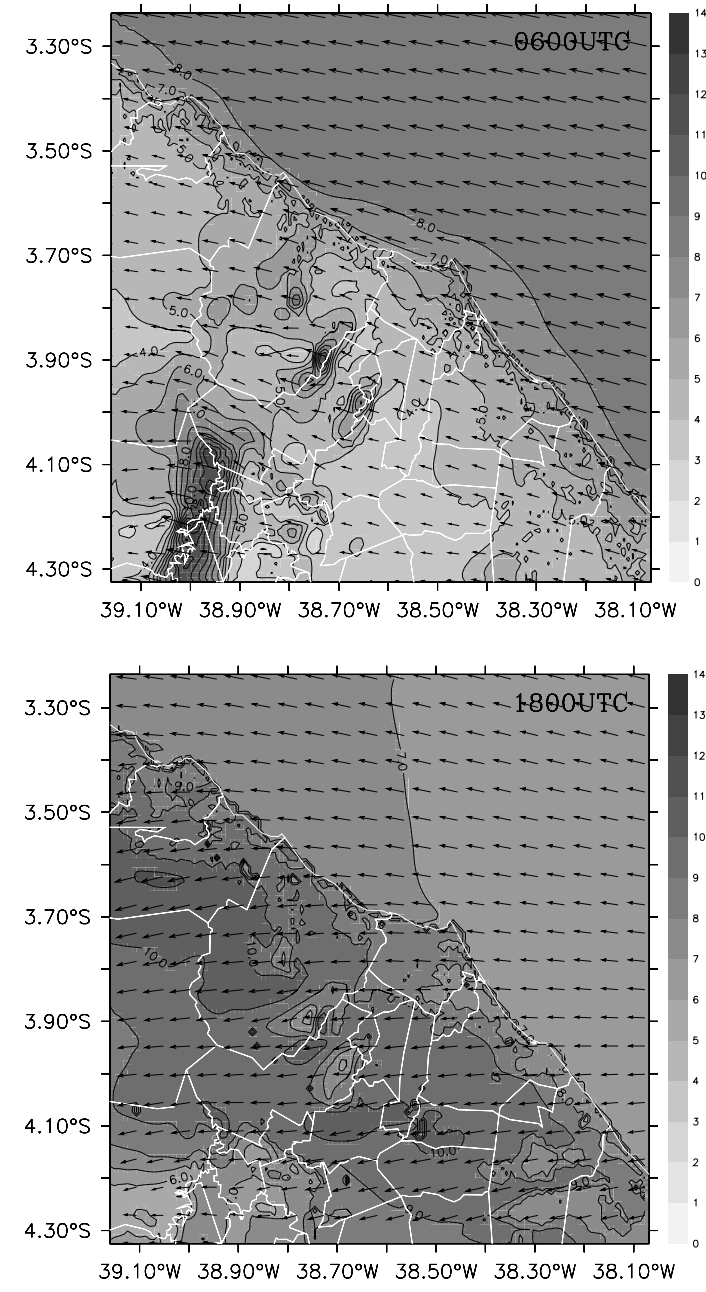

c)

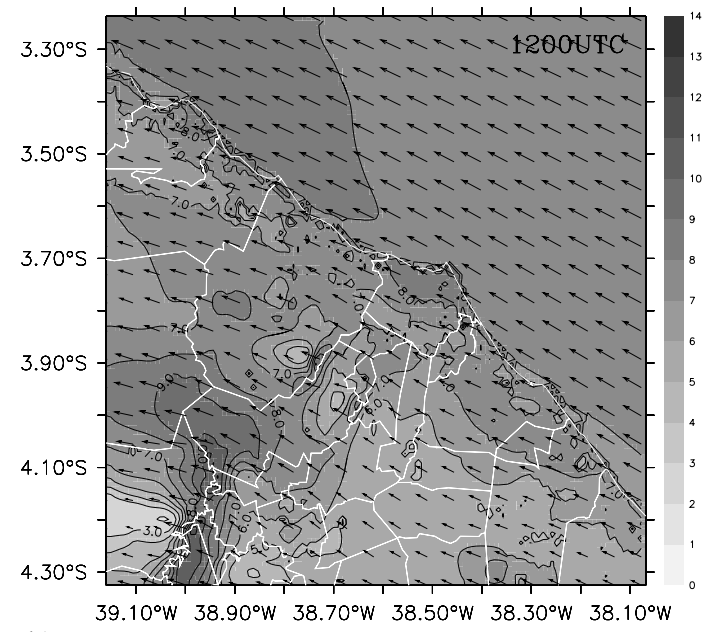

b)

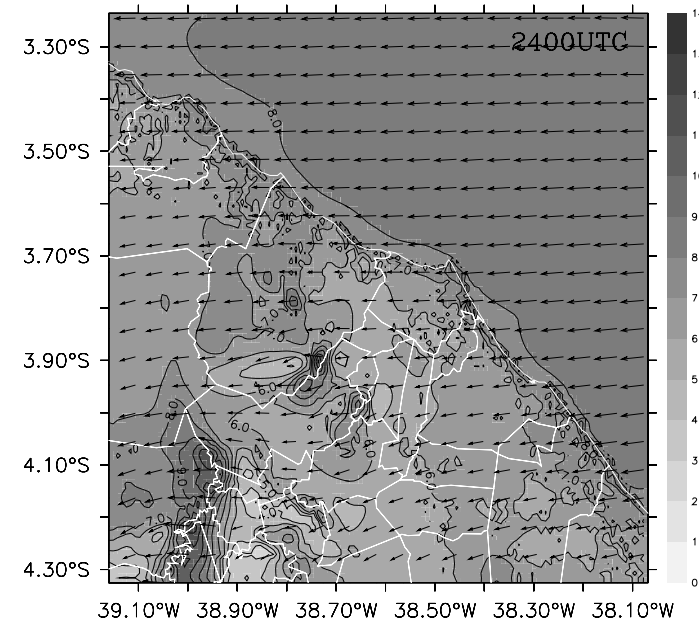

d)

Figura 8 - Campo de vento a $60 \mathrm{~m}$ da superfície para a Grade 3, com a direção do vento indicada pelos vetores, a topografia representada pelas curvas de nível em branco e a divisão política em linha preta, em média para os 4 dias simulados.

Tabela 9 - Intercomparação das opções do relaxamento newtoniano. Índices estatísticos para velocidade e direção do vento nas localidades de Paracuru e Camocim, para o nível de $60 \mathrm{~m}$ acima da superfície.

\begin{tabular}{|c|c|c|c|c|c|c|c|c|c|c|c|}
\hline & & Opção & $b$ & $A$ & $E$ & $R_{\sigma}$ & $A_{d^{\prime}}$ & $E_{d}$ & $I_{c}$ & $R$ & Esc. \\
\hline \multirow{6}{*}{ 崫 } & \multirow{3}{*}{$\Phi$} & $\mathrm{s} / \mathrm{nud}$ & $-0,60$ & 2,20 & 2,90 & 0,66 & 2,03 & 2,80 & 0,28 & $-0,21$ & 2 \\
\hline & & $\mathrm{t}=24 \mathrm{~h}$ & $-1,88$ & 1,94 & 2,24 & 1,69 & 0,99 & 1,20 & 0,50 & 0,53 & 0 \\
\hline & & $\mathrm{t}=12 \mathrm{~h}$ & $-1,62$ & 1,71 & 2,03 & 1,52 & 0,99 & 1,20 & 0,54 & 0,54 & 13 \\
\hline & \multirow{3}{*}{$\nexists$} & $\mathrm{s} / \mathrm{nud}$ & 36,25 & 36,29 & 42,67 & 0,36 & 21,05 & 22,50 & 0,32 & 0,60 & 0 \\
\hline & & $\mathrm{t}=24 \mathrm{~h}$ & 3,33 & 5,94 & 7,92 & 1,29 & 5,70 & 7,17 & 0,79 & 0,69 & 3 \\
\hline & & $\mathrm{t}=12 \mathrm{~h}$ & 4,70 & 6,64 & 8,39 & 1,08 & 5,61 & 6,93 & 0,81 & 0,74 & 12 \\
\hline \multirow{6}{*}{8} & \multirow{3}{*}{$\overline{8}$} & $\mathrm{~s} / \mathrm{nud}$ & $-2,20$ & 2,99 & 3,83 & 1,55 & 2,57 & 3,13 & 0,65 & 0,53 & 0 \\
\hline & & $\mathrm{t}=24 \mathrm{~h}$ & $-2,16$ & 2,64 & 3,05 & 1,56 & 1,75 & 2,16 & 0,77 & 0,83 & 1 \\
\hline & & $\mathrm{t}=12 \mathrm{~h}$ & $-2,20$ & 2,55 & 2,98 & 1,54 & 1,64 & 2,01 & 0,79 & 0,86 & 14 \\
\hline & \multirow{3}{*}{ 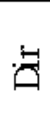 } & $\mathrm{s} / \mathrm{nlud}$ & 30,25 & 36,15 & 46,57 & 0,81 & 30,55 & 35,41 & 0,52 & 0,30 & 0 \\
\hline & & $\mathrm{t}=24 \mathrm{~h}$ & $-9,72$ & 11,91 & 17,22 & 1,25 & 10,46 & 14,21 & 0,87 & 0,85 & 0 \\
\hline & & $\mathrm{t}=12 \mathrm{~h}$ & $-6,87$ & 9,50 & 13,40 & 1,17 & 8,14 & 11,50 & 0,92 & 0,90 & 15 \\
\hline
\end{tabular}




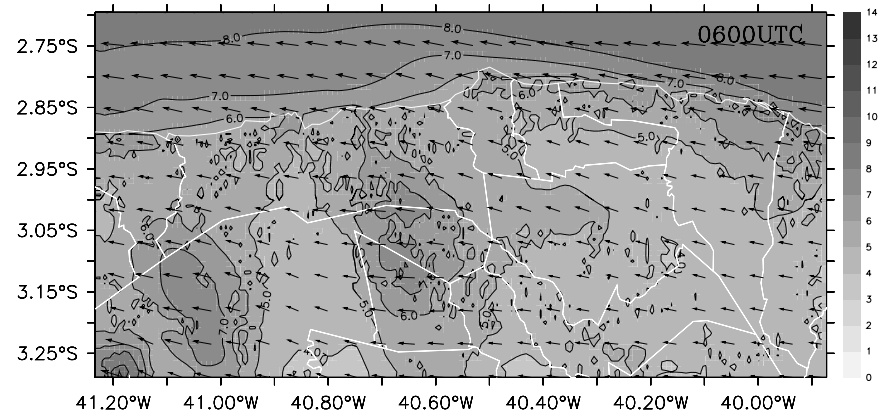

a)

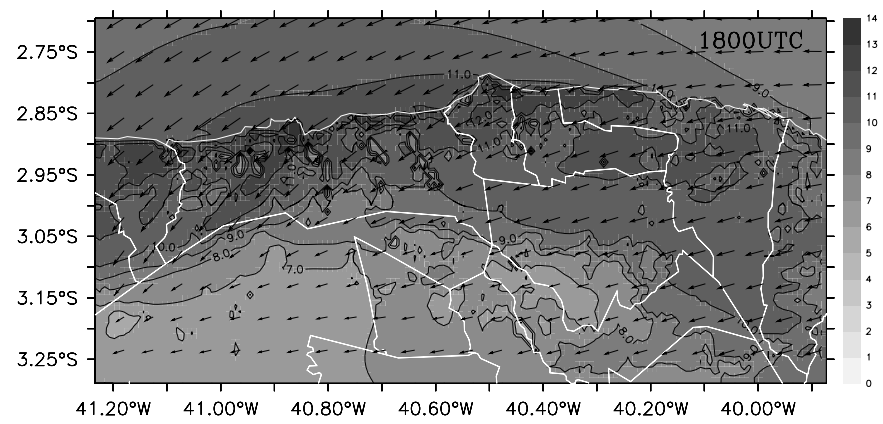

c)

Figura 9 - Assim como a Figura 8, mas para a grade 4.

mais evidente, especialmente pela variação que se detecta entre as 12 UTC (b) e as 18 UTC (c). Novamente, a topografia mostra sua influência nos padrões espaciais da intensidade do vento, que se percebe na uniformidade sobre o oceano e na significativa variabilidade sobre o continente.

\section{CONCLUSÕES}

Os testes de sensibilidade mostram bons resultados com qualquer das opções - exceto quando desligado o relaxamento newtoniano - ficando evidente que um menor espaçamento de grade é responsável pela representação mais realista dos campos de vento. Como se pode ver pelas Tabela 6 e 7, o esquema proposto por Smagorinsky apresenta melhores índices estatísti-cos, especialmente quando mais próximo da faixa litorânea. Pode-se ainda verificar a consistência da metodologia estatística ao atribuir mais escores à opção que se apresenta como melhor. Ao mesmo tempo, a metodologia estatística mostrou-se consistente ao atribuir mais escores à opção que se mostrava melhor já no gráfico da série temporal. A expectativa é que este procedimento se mostre particularmente útil em casos onde não é possível, por meios apenas visuais, a determinação dos melhores resultados.

Esses resultados são particularmente úteis na escolha dos parâmetros a serem usados no modelo RAMS, seja para previsão de tempo ou previsão de geração de energia

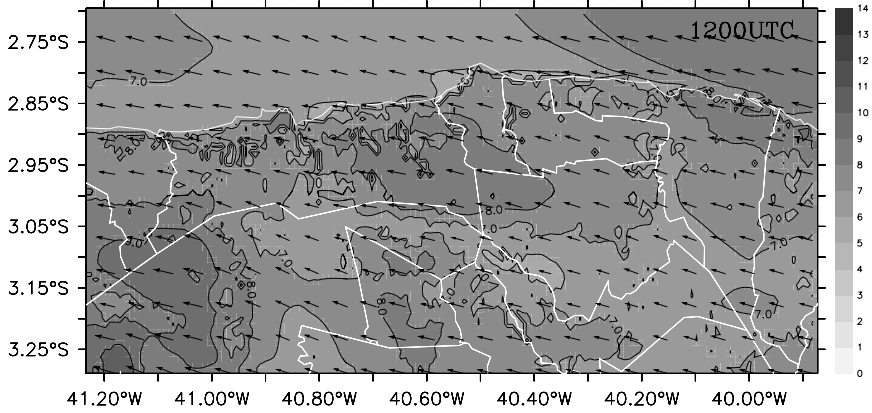

b)

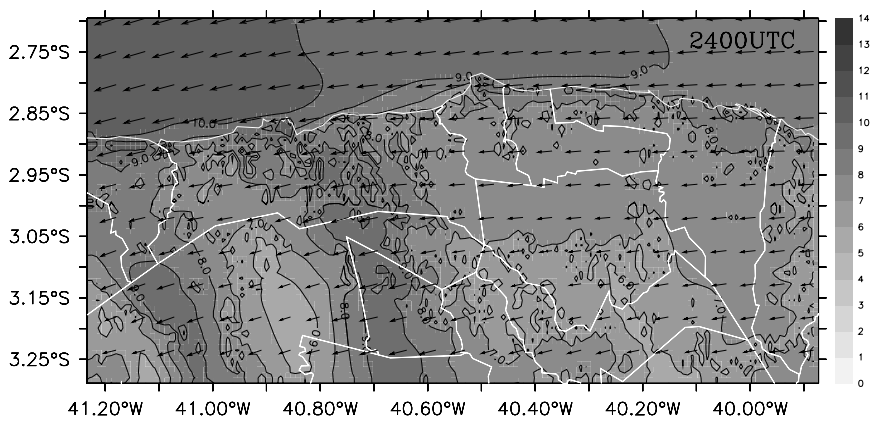

d)

eólica, por se tratar da utilização de um método objetivo de comparação de modelos. Entretanto, outros parâmetros podem ser determinantes na obtenção de melhores resultados, o que demandaria mais testes.

\section{AGRADECIMENTOS}

O presente artigo fez parte do trabalho de dissertação do primeiro autor junto ao curso de Mes-trado em Ciências Físicas Aplicadas (MCFA) da Universidade Estadual do Ceará (Ueec). Os autores agradecem à Fundação Cearense de Apoio ao Desenvolvimento Científico e Tecnológico (Funcap), ao Conselho Nacional de Desenvolvimento Científico e Tecnológico (CNPq) e à Financiadora de Estudos e Projetos (FINEP) pelo suporte.

\section{REFERÊNCIAS BIBLIOGRÁFICAS}

ATLAS DO POTENCIAL EÓLICO DO ESTADO DO CEARÁ, Governo do Estado do Ceará - Secretaria da Infraestrutura. CD ROM, 2001.

BUCKLEY, R. L.; WEBER, A. H.; WEBER, J. H. Statistical comparison of Regional Atmos-pheric Modeling System forecasts with observations. Meteorological Applications, v. 11, n. 1, p. 67-82, mar. 2004. 
CONSÓRCIO BRASELCO-MELQART-CKC. Projeto Paracuru: Instalação e comissiona-mento de Torre Anemométrica No. 8550. Relatório técnico, 2004a.

CONSÓRCIO BRASELCO-MELQART-CKC. Projeto Camocim: Instalação e comissiona-mento de Torre Anemométrica No. 8551. Relatório técnico, 2004b.

COTTON, W. R.; PIELKE Sr., R. A.; WALKO, R. L.; LISTON, G. E.; TERMBACK, C. J.; JIANG, H.; MCANELLY, R. L.; HARRINGTON, J. Y.; NICHOLLS, M. E.; CARRIO, G. G. RAMS 2001: Current status and future directions. Meteorology and Atmospheric Phys-ics, v. 82, n. 1, p. 529, 2003.

GIEBEL, G. The state-of-the-art in short-term prediction of Wind Power - A literature over-view. Risø National Laboratory, 2003.

HARRINGTON, J. Y.; MEYERS, R. L.; WALKO, R. L.; COTTON, W. R. Parameterization of ice crystals conversion processes due to vapor deposition for mesoscale models using dou-ble-moment basis functions. I- Basic formulation and parcel model results. Journal of the Atmospheric Sciences, v. 52, n. 23, p. 4344-4366, dez. 1995.

JOLLIFFE, I. T.; STEPHENSON, D. B. Forecast verification: a practitioner's guide in at-mospheric sciences. Wiley, 2003. 254p.

KUO, H. L. Further Studies of the Parameterization of the Influence of Cumulus Convection on Large-Scale Flow. Journal of the Atmospheric Sciences, v. 31, n 5, p. 12321240, jul. 1974.

MELLOR, G. L.; YAMADA, T. A Hierarchy of Turbulence Closure Models for Planetary Boundary Layers. Journal of the Atmospheric Sciences, v. 31, n 7, p. 1791-1806, out. 1974.

MELLOR, G. L.; YAMADA, T. Development of a turbulence closure model for geophysical fluid problems. Reviews of Geophysics and Space Physics, v. 20, p. 851-875, 1982.

ACCIOLYFILHO, J.B.P.; MENDES, F.J.;SAKAMOTO, M. S.A rede de estações meteo-rológicas da FUNCEME. In: Congresso Brasileiro de Meteorologia, 2004, Fortaleza. Anais XIII CONGRESSOBRASILEIRO DE METEOROLOGIA, 2004.
PIELKE, R.A.; COTTON, W. R.; WALKO, R. L.; TREMBACK, C. J.; LYONS, W. A.; GRASSO, L. D.; NICHLLS, M. E.; MORAN, M. D.; WESLEY, D. A.; LEE, T. J.; COPELAND, J. H. A comprehensive meteorological modeling syste-RAMS. Meteorology and Atmospheric Physics, v. 49, n. 1, p. 69-91, 1992.

PIELKE, R. A. Mesoscale Meteorologial Modeling. Academic Press, 2002. 750p.

SÁ, A. L. Atlas do Potencial Eólico Brasileiro. DEWI Magazine, no. 19, p. 63-73, 2001.

SÁNCHEZ, I. Short-term prediction of wind energy production. International Journal of Pre-diction, v. 22, n. 1, p. 43-56, 2006.

SMAGORINSKY, J. General Circulation Experiments with the Primitive Equations. I- The Basic Experiment. Monthly Weather Review, v. 91, n. 3, p. 99-164, mar. 1963.

STEYN, D. G.; MCKENDRY, I. G. Quantitative and Qualitative Evaluation of a Three-Dimensional Mesoscale Numerical Model Simulation of a Sea Breeze in Complex Terrain. Monthly Weather Review, v. 116, n. 10, p. 1914-1926, out. 1988.

WALKO, R. L.; BAND, L. E.; BARON, J.; KITTEL, T. G. F.; LAMMERS, R.; LEE, T. J.; OJIMA, D.; PIELKE Sr, R. A.; TAYLOR, C.; TAGUE, C.; TREMBACK, C. J.; VIDALE, P. L. Coupled Atmosphere-Biophysics-Hydrology Models for Environmental Modeling. Journal of Applied Meteorology, v. 39, n. 6, p. 931-944, jun. 2000.

WALKO, R. L.; COTTON, W. R.; MEYERS, M. P.; HARRINGTON, J. Y. New RAMS cloud microphysics parameterization part I: the single-moment scheme. Atmospheric Research, v. 38, n. 1, p. 29-62, 1995.

WEBER, A. H.; BUCKNER, M. R.; WEBER, J. H. Statistical Performance of Several Mesos-cale Atmospheric Dispersion Models. Journal of Applied Meteorology, v. 21, n. 11, p. 1633-1644, nov. 1982.

WILLMOTT, C. J. Some Comments on the Evaluation of Model Performance. Bulletin of the American Meteorological Society, v. 63, n. 11, p. 1309-1313, nov. 1982. 